\title{
Lifetime analysis of WWER Reactor Pressure Vessel Internals concerning material degradation
}

\author{
Szabolcs Szávai ${ }^{a}$, Judit Dudrab \\ ${ }^{a, b}$ Department of Structural Integrity, Bay Zoltán Foundation for Applied Research, \\ Institute for Logistics and Production System, Miskolctapolca, Hungary, \\ e-mail: szavai.szabolcs@bay-logi.hu
}

Keywords: RVI, neutron irradiation, lower core barrel, core basket, baffle, guide tubes, ageing mechanisms.

\section{ABSTRACT}

The internal structures of water reactors play an important role as they contain the core of the reactor, they channel the water flow inside the vessel and they support and guide the instrumentation necessary for controlling and monitoring the reactor.

Long-term aging at WWER operating temperatures results in changes in microstructure and phase composition, and, hence, mechanical properties of structural steels for WWERs. Besides Reactor internals are subject of three principle operation influences: neutron and gamma irradiation, static and dynamic mechanical stresses and coolant chemistry.

Design basis for the reactor internals in WWERs did not calculated with any ageing of these structures due to that time unknown mechanisms of degradation.

In this study we shall negotiate the effect of these mechanisms for WWER 440 RVI and present lifetime analysis in order to extend the operational lifetime of RVI.

\section{PRELIMINARIES}

This study aims to extend the operational lifetime of its WWER 440 type Units. Technical margins, the inherent safety and the realized safety improvement measures provide an opportunity for the extension of operational lifetime of the nuclear power plant.

Namely, the purpose of this task is to perform evaluative analyses of presumable changes in material properties of WWER $440 \mathrm{RVI}$. In accordance with these, this study answers the question: are there any degradation mechanisms, which limit the lifetime of the structural elements of RVI.

Nowadays it is a very important research area, but the available literature does not contain enough information of failures of WWER RVI. Within the frame of this we consider the followings:

- systematization of structural plans and basic data needed for the analysis, determination of initial data for analyses;

- investigation of the presumable changes in material properties of the RVI;

- perform strength and fatigue analyses of critical structural elements of RVI;

- estimate the technically possible operation time of the structural elements considering the operation load of the 50 and 60 years operation time.

Basically, the strength and fatigue analyses should be performed in accordance with the provisions of the ASME (ASME III (2001)). Calculation methodologies of these structures consist of strength analysis, fatigue analysis and thermal stratification analysis for systems and components. 


\section{THE STRUCTURE ELEMENTS UNDER CONSIDERATION, BOUNDARIES OF ANALYSES}

The subject under consideration of this study are the reactor vessel internals of WWER 440, namely the guide tubes, core barrel, core basket and lower core barrel constructions (see Figure 1.).

Analysis boundaries: the edge boundaries of the WWER 440 RVI and its non weld joints.

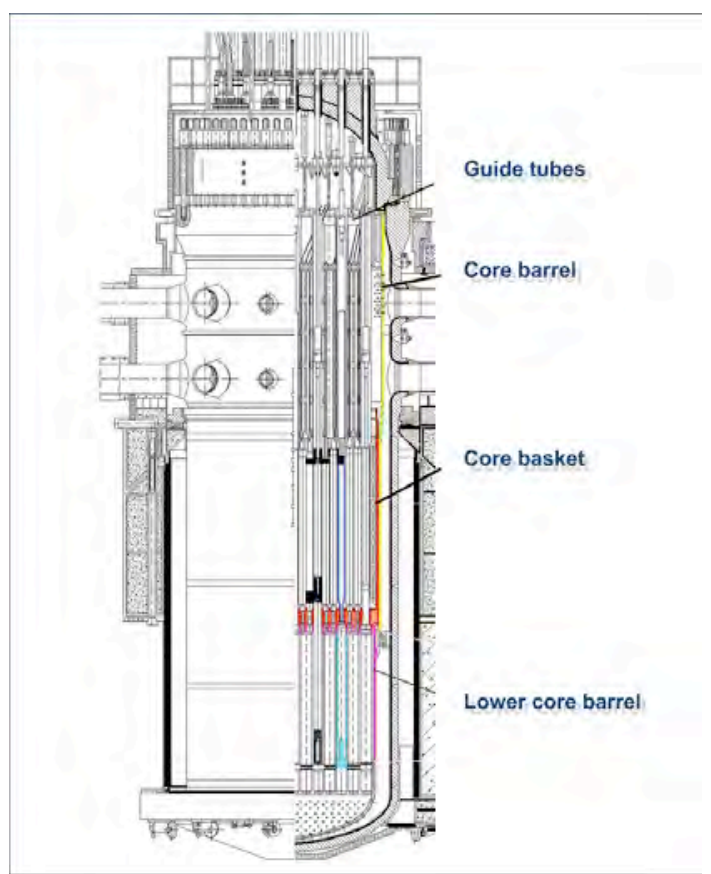

Figure 1. Construction of WWER 440 RPV and internals

\section{POTENTIAL DEGRADATION, MATERIAL MODELS AND EVALUATIONS}

In the following we summarize the possible ageing mechanisms of WWER 440 RVI (Figure 2.). Evaluation of these mechanisms is based on service experience, pertinent laboratory data and relevant experience from other industries.

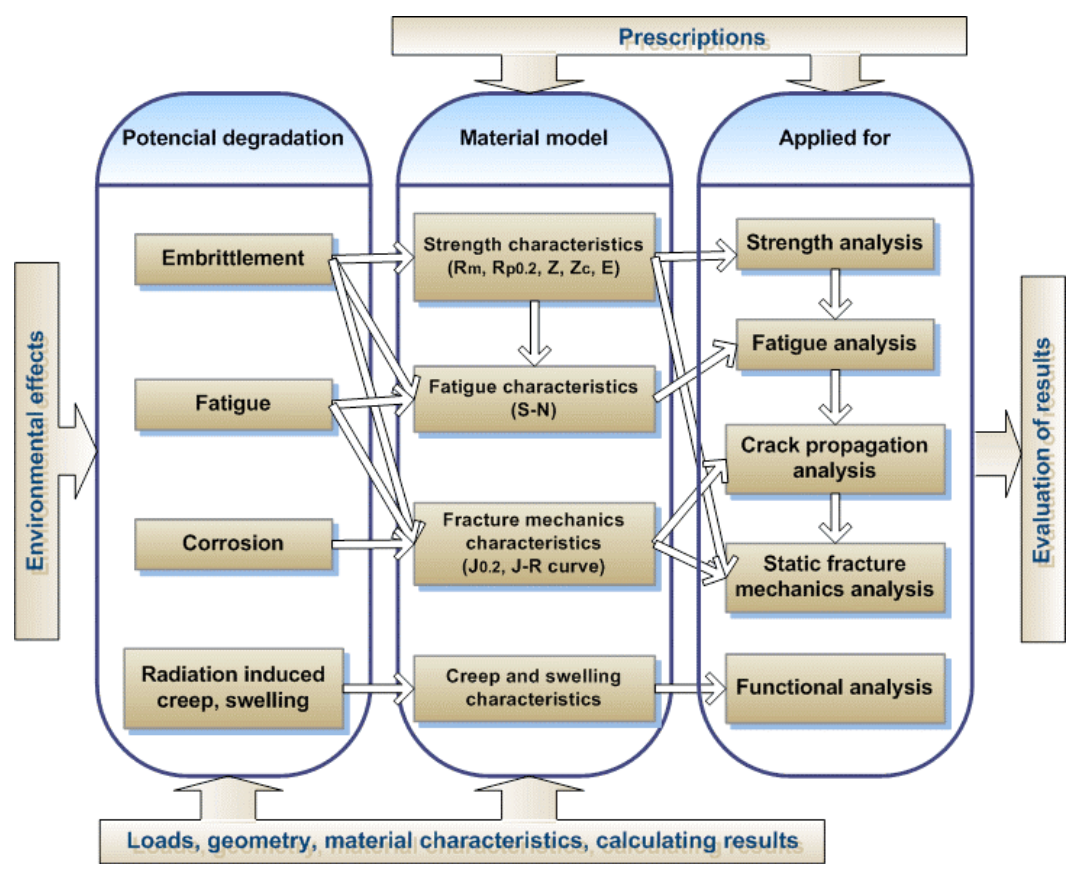

Figure 2. Evaluation methodology 
During the evaluation we examine the following: how influence the changes of the material characteristics not only the strength and fatigue analysis, but the size of the allowable cracking and the velocity of the crack propagation in case of operation or breakdown.

The austenitic steels and the base material of the reactor internals are characterized by ductile fracture mode. At the same time the effect of irradiation causes embrittlement mechanisms in the material, which can lead to decrease of the toughness of the material. These embrittlement mechanisms can decrease the Charpy test values and the $\mathrm{J}-\mathrm{R}$ curve (and $\mathrm{J}_{0.2}$ ). The $\mathrm{J}-\mathrm{R}$ curve can be applied (beside the strength material characteristics) to the investigation of the stableness of the crack or the stable crack propagation. To evaluate the stability of the crack propagation two parameters Failure Assessment Diagram are applicable.

\section{LOADS AND MATERIAL CHARACTERISTICS}

Within the framework of the study the analysis are made by mean of the load catalogue (beside $100 \%$ and $108 \%$ power), which identify the loads, determine load curves and load cycle numbers for cyclic loads expected during the planned extended lifetime.

The main structural material used for WWER 440 for RVI is titanium stabilized austenitic stainless steel 08Ch18N10T (equivalent to A-321); minor parts were made from nickel alloy ChN35VT-VD (this material is used for studs and is tungsten alloyed) and the steel 14Ch17N2. The weld metals Sv08Ch19N10G2B and Sv04Ch19N11M3 were used.

\subsection{Static strength material characteristics and crack growth under static load}

The RVI suffer by several degradation mechanisms in course of reactor operation, from among these the most serious problem is the change of material properties and J-R curve due to neutron irradiation. The requested data to characterize the operational change of material properties means the material changes due to irradiation. To perform the calculations the material characteristics and J-R curve should be determined concerning 50 and 60 years relevant to the expected maximum fluence.

\subsection{Material characteristics concerning resistance of the fatigue crack propagation}

According to the ASME Code XI:2001 C 3210-1 and other experimental results of the investigation, which were performed in inner atmosphere (in cooling water) of the WWER 440 and on laboratory air, the ratio of the velocity of the crack propagation is around 2,5. Making use of this constant ratio $(2,5)$ we determine the curve of the crack propagation concerning the heat-transfer media.

\subsection{Material characteristics concerning the resistance of the stress corrosion crack propagation}

After longer operation, the appearance of stress corrosion cracking cannot be excluded in the reactor vessel internals. This crack propagation is function of the temperature, the media and other outer effects, like the neutron irradiation. To investigate the possibility of the crack propagation the threshold of the $\mathrm{K}_{\mathrm{ISCC}}$ stress intensity factor is needed.

\section{FUNCTIONAL TEMPERATURE AND FLUENCE INFORMATION}

The nominal inlet and outlet temperatures in the reactor vessel: 267/296 Celsius $-100 \%$ power, 267/299 Celsius $-108 \%$ power.

Former research results of neutron physics calculations concern the position of the wall of the reactor vessel. The fluence of the test sample estimated for 60 years practically equals with the load of the outer surface of the core barrel, and it is $\sim 12 \mathrm{dpa}$. On the basis of study (2) it can be proved that the fluence value of the core boundary can be multiplied ( 5-10) of the value of the core barrel, namely it can be estimated 3560 dpa for 60 years operation time.

According to the NRI study (3), which concerns the destruction analysis of the basket of the Greifswald Unit 1., the fluence value of the basket is the following: "The calculated maximum dose for the baffle 
component of Greifswald Unit 1 internals after 15th operation cycle according one calculation method is $1.2 * 1026 \mathrm{~m}-2(\mathrm{E}>0.5 \mathrm{MeV})$, i.e. $11.4 \mathrm{dpa}(4)$, and according a second method is $1.3 * 10^{26} \mathrm{~m}-2(\mathrm{E}>1.0$ $\mathrm{MeV}$ ), i.e. 19.4 dpa (5)".

During the analysis first step is to define the maximum neutron fluence values of the critical place of the RVI for 50 and 60 years operation time. To the calculations the resulted material characteristics relevant to the maximum fluence will be applied.

The KFKI Atomic Energy Research Institute (AEKI) has made calculations concerning critical environments of the structural elements of RVI in order to determine the expected maximum fluence value. The analyses were made for 30, 50 and 60 years operation time. The irradiation dose was defined in dpa unit (displacement per atom) and the next table contains the results of the measurements:

Table 1. The irradiation dose on the place with maximum dose

\begin{tabular}{llllll}
\hline \multirow{2}{*}{$\begin{array}{l}\text { Irradiation time } \\
\text { [year] }\end{array}$} & $\begin{array}{l}\text { Bolt head, } \\
\text { baffle }\end{array}$ & $\begin{array}{l}\text { Shank of } \\
\text { the bolt }\end{array}$ & $\begin{array}{l}\text { Core } \\
\text { basket }\end{array}$ & $\begin{array}{l}\text { Lower } \\
\text { core } \\
\text { barrel }\end{array}$ & $\begin{array}{l}\text { Core } \\
\text { plate 2-3 }\end{array}$ \\
\hline 30 & 42 & 36 & 34 & 14 & 36 \\
\hline 50 & 75 & 61 & 58 & 24 & 61 \\
\hline 60 & 91 & 73 & 70 & 29 & 73 \\
\hline
\end{tabular}

Based on the estimation, the results show $20 \%$ decrease in the bolt head and $40 \%$ decline in the shank of the bolt in radial direction. The estimated irradiation value at the bolt neck is circa $85 \mathrm{dpa}$.

\section{AVAILABLE MATERIAL DATA AND MATERIAL CHARACTERISTICS CONCERNING 50 AND 60 YEARS OPERATION TIME}

The base metals (A304, A304L, A316, A316L, A316Ti) of RVI of Western type reactors are non stabilized and/or non titanium stabilized austenitic steels, and cannot be considered to be equivalent with materials applied in WWER type. On the basis of the previous overview of the available analytical and research results (2)(3) the danger cannot be excluded that higher neutron fluence can cause embrittlement which leads to change the method of the austenitic steel fracture and occurs intergranular type fracture mechanism in the material. To avoid this concrete examination results, material characteristics are needed for high fluence value.

Available examination results regarding to RVI of NRI REZ and Prometey Institute for 50-60 operation years are the follows:

a) Tensile test $\rightarrow \sigma-\varepsilon$, YS, UTS, A, RA, fracture mode.

b) Instrumented Impact test $\rightarrow \mathrm{KV}, \mathrm{KCV}$.

c) Fracture resistance $\rightarrow \mathrm{J}_{0.2}, \mathrm{~J}-\mathrm{R}$, fracture mode.

During the calculations we have defined the material characteristics of the core barrel, core basket, shank of the bolt, bolt head and core plate concerning 50 and 60 years operation time relevant to the expected maximum fluence (based on the NRI, Prometey measurement and other data available in the literature).

In accordance with the above mentioned we have determined:

a) strength characteristics (YS, UTS and RA) as a function of the size of irradiation. These material characteristics show growing (except the RA, which shows decreasing) until these turn into saturation (after $60 \mathrm{dpa}$ ).

b) fatigue curves based on strength characteristics. Our investigations show that the calculated fatigue curves run above the fatigue curve according to PNAE. In this manner the earlier fatigue analyses will be valid for the 50-60 years operation time. In the following we announce only the curve belonging to the 60 years operation time according to $r=0$ (see Figure 3.). 


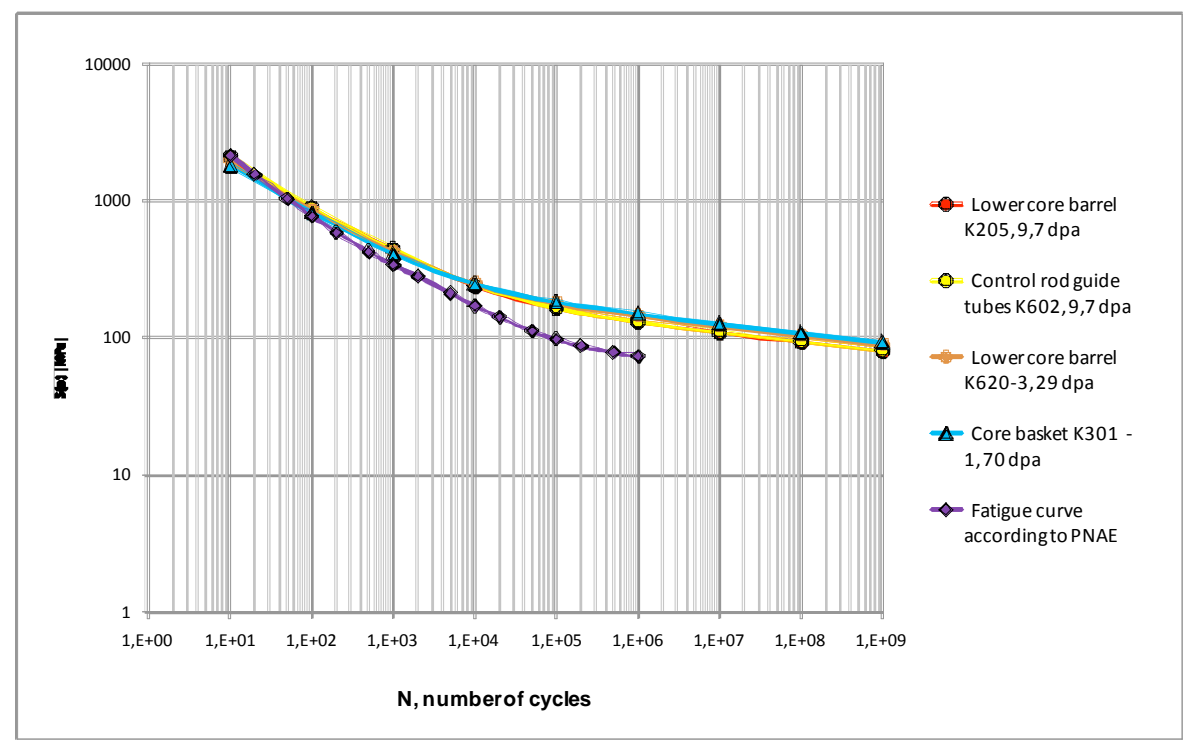

Figure 3. Fatigue curves concerning 60 years operation time, $r=0$

c) We also determined the $J c$ static crack growth resistance and the $K_{J C}$ stress intensity factor as a function of the size of irradiation. For example for $30 \mathrm{dpa} \mathrm{J}_{\mathrm{C}}=15 \mathrm{kJm}^{-2}$ and $\mathrm{K}_{\mathrm{JC}}=51 \mathrm{MPa} \sqrt{\mathrm{m}}$ (for the base metal), and both material characteristics turn into saturation over 30-35 dpa (in case of the base metal and the weld material too).

d) We defined the swelling characteristics of the analysed materials concerning 50-60 operation time. The value of the swelling for $30 \mathrm{dpa}$ in the course of lower core barrel is $0,3 \%$, core basket for 57 dpa $1,1 \%$ and the bolt head for 75 dpa the swelling is $1,8 \%$.

In case of material characteristics $\left(\mathrm{K}_{\mathrm{ISCC}}\right.$; da/dt-K) concerning crack propagation and crack initiation assist environment effect: determination of these material characteristics are based on concrete measurement results. However there are no measurement data in the literature. Therefore we set out from the earlier conservative approach, where author use $3 * 10^{-11} \mathrm{~ms}^{-1}$ value for the velocity of the crack propagation independently from the load.

\section{PREVIOUS ASSESSMENT OF THE PRESUMABLE CHANGING MECHANISMS OF MATERIAL PROPERTIES OF RVI}

The degradation of the material characteristics and the degradation of the components are the result of complex environmental effects. The hardening and embrittlement, fatigue and environmental effects (corrosion cracking and propagation) appear as the effect of the irradiation, those are degradation mechanisms, and analysis of these mechanisms are needed and very important.

\subsection{Analysis borders}

During the analysis we selected at least one most critical environment in case of any structural elements, onto which we did the fracture mechanics calculations. If the cross-section did not coincide with the high of the zone where the largest irradiation is expected, then we have selected a second critical cross-section of the structural element with the high of the zone.

\subsection{Necessary calculations - Analysis of stable crack propagation}

As we already mentioned the effect of irradiation causes embrittlement mechanisms in the material, which can lead to decrease of the toughness of the material. These mechanisms can decrease the Charpy test values and the J-R curve (and $\mathrm{J}_{0.2}$ ). The J-R curve can be applied (beside the strength material characteristics) to the investigation of the stableness of the crack or the stable crack propagation. To evaluate the stability of the crack propagation two parameters Failure Assessment Diagram are applicable. 
While the RVI are not pressure element, it is practical to assume that the material has through crack. The ASME standard does not contain any information about the calculation of through crack, therefore we have applied the FITNET European Union Standard Collection in the course of calculations.

The basis of the determination of the allowable crack length was the $\mathrm{K}_{\mathrm{I}}$ stress intensity factor. We have determined the stress intensity factor supposing different crack length for every single dangerous environment. Using this information we were able to define crack size which is possible to allow in the construction under 60 years operation. In possession of the FAD (failure assessment diagram) the calculation of the allowable crack size can be calculated in the critical environment of the structural element. The following table contains the allowable crack lengths in some instances.

Table 2. The allowable crack sizes in some critical environments

\begin{tabular}{lllll}
\hline Environment & $\mathbf{T},{ }^{\circ} \mathbf{C}$ & $\begin{array}{l}\text { Irradiation } \\
{[\mathbf{d p a}]}\end{array}$ & $\begin{array}{l}\text { Operation } \\
\text { condition }\end{array}$ & $\begin{array}{l}\text { allowable crack } \\
\text { size [mm] }\end{array}$ \\
\hline $\begin{array}{l}\text { Lower core barrel } \\
\text { K205 }\end{array}$ & 295 & 9,7 & tv10* & 544 \\
\hline $\begin{array}{l}\text { Control rod guide tubes } \\
\text { K602 }\end{array}$ & 262 & 9,7 & tv10* & 1280 \\
\hline $\begin{array}{l}\text { Lower core barrel } \\
\text { K620-3 }\end{array}$ & 275 & 29 & tv10* & 542 \\
\hline Core basket K301-1 & 332 & 70 & $\begin{array}{l}\text { NA500 heat circuit } \\
\text { fracture* }\end{array}$ & 82 \\
\hline
\end{tabular}

* Final safety report / Load Catalogue data

The appearing allowable crack sizes are still enough large to recognize with visual examination. The examinations did not reveal these cracks neither in the marked environments, neither somewhere else in the RVI components.

\subsection{Fatigue crack propagation analyses}

In point of data relative to fatigue crack propagation, concrete measurement results are needed. Since the operating load cycles do not cause neither significant load, neither large number of cycles and the CUF value is much smaller than 0.2 , thus these do not cause fatigue crack propagation. The crack propagation can result only from the vibration of the reactor internals, if the vibration load effects larger stress intensity factor change than the threshold SIF of the fatigue crack propagation $\left(\Delta \mathrm{K}_{\mathrm{th}}\right)$. The vibration caused numbers of cycles are as big that the small crack propagation velocity can cause promptly a larger crack size. Therefore the allowable crack size has to be as large that the vibration load cannot cause crack propagation.

According to the calculations the fatigue crack propagation does not cause so large crack which could cause stable or instable crack propagation in case of zone basket and lower core plate. The currently known examinations did not reveal cracks in the dangerous cross-section of the control rod guide tubes and lower core barrel.

\subsection{Stress corrosion crack propagation analyses}

After longer operation in the reactor vessel internals cannot be excluded the appearance of the stress corrosion cracking. We have performed stable crack propagation analysis for the crack appearing in fastener bolts. The ASME standard does not contain information regarding calculation of the crack appearing in bolt, thus the calculations were performed according to the FITNET standard, based on the BS 7910 procedure. The stress of the shank of a bolt equals the allowable maximum tensile stress value (according to PNAE standard), which is half of the planning yield stress.

During the calculations we have determined the value of the stress intensity factor, then from this we calculated the J Integral- and fracture toughness of the material as a function of irradiation dose. As well as we have also determined the $\mathbf{J}_{0.2}$ value belonging to the fracture, then we have plotted these values as a function of elapsed time.

We have determined that how much time elapses from the crack appearance while the crack with fatigue-corrosion crack propagation reaches the section of the stable crack propagation. The operation time of the bolt depends on a large scale on the form of the crack. When we consider the worst case, namely when 
we calculate with circular crack, approximately the bolt get in 3,5 years into the stable crack propagation phase (Figure 4.). When we consider straight crack front, approximately the bolt get in 6,1 years into the stable crack propagation phase (Figure 4).

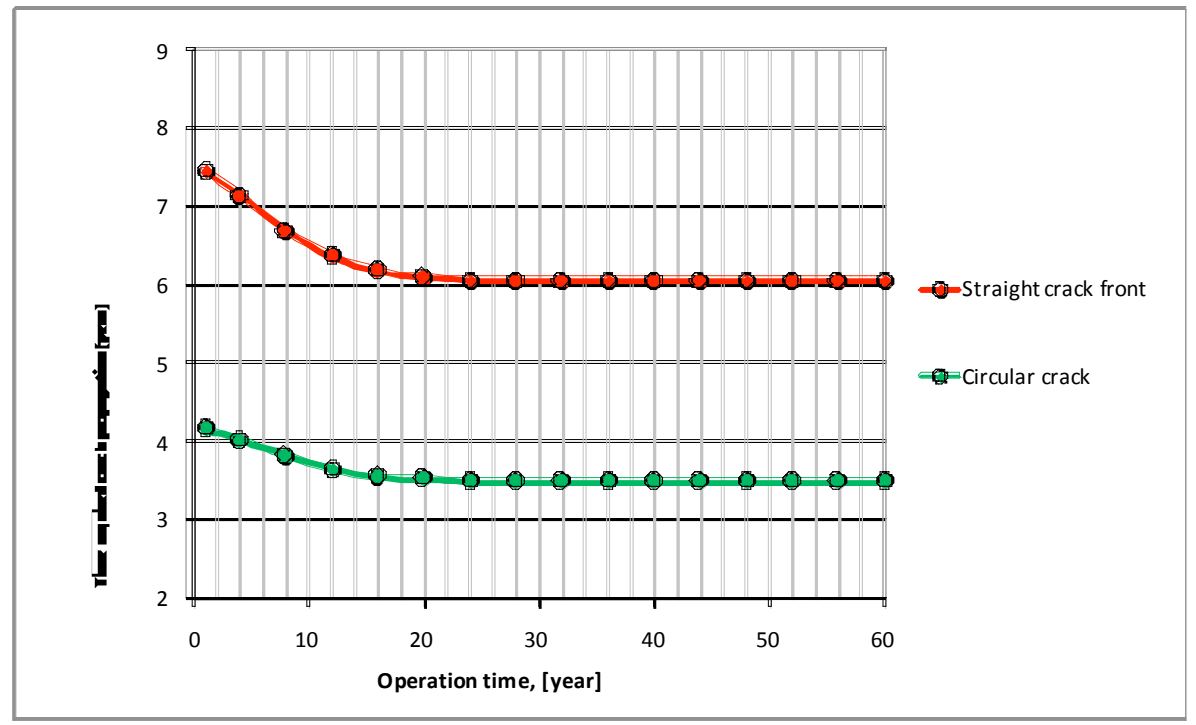

Figure 4. Time required allowable stress corrosion crack size

\subsection{Effect of swelling}

The swelling will appear primarily in the component exposed to high gamma irradiation. We have determined the changes of the swelling appearing in the wall of the basket in order to demonstrate the distribution of the swelling of the wall. In the wall of the basket (at the half of the height of the zone) can be described the swelling along the wall with the help of the swelling relation given by Prometey Institute (6), assuming that the value of the irradiation can be decreased with $40 \%$ in the wall.

The next figure shows the swelling distribution in the wall of the basket regarding 50-60 years operation time. The appearing swelling can cause second stress in the material.

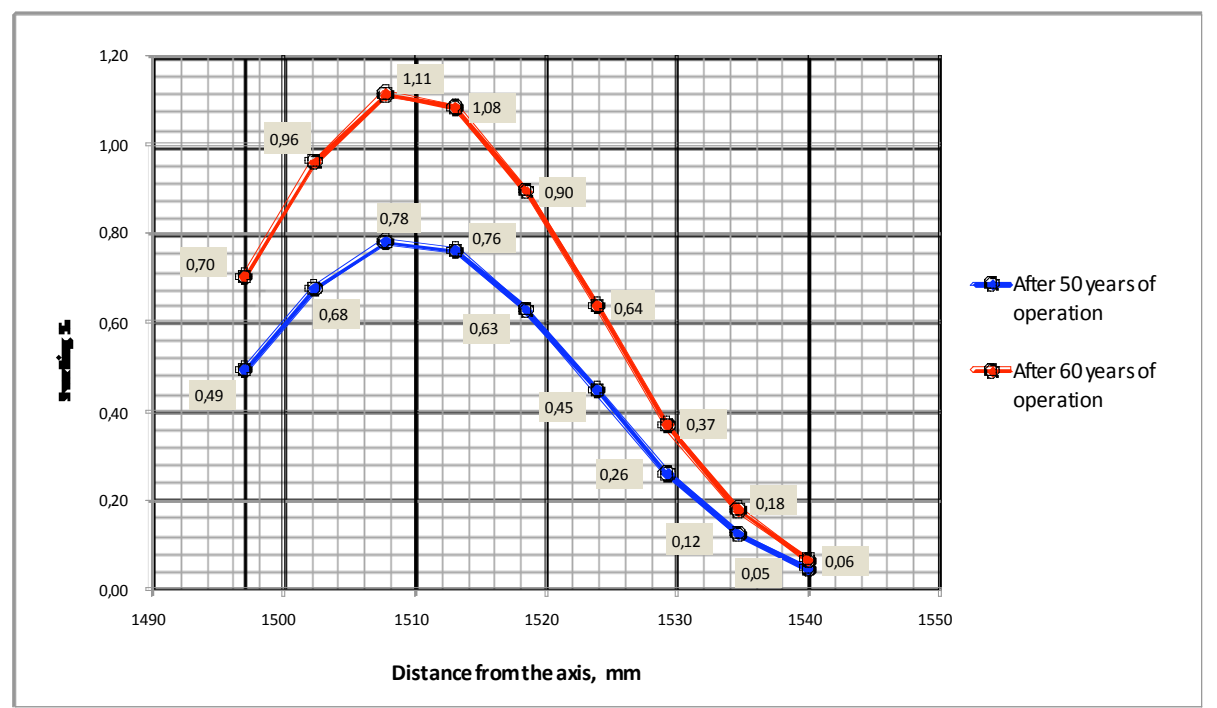

Figure 5. Swelling occurred after 50-60 years operation in the wall of the basket 


\section{CONCLUSION}

We have examined the presumable changes in material properties of the RVI, and estimated the technically possible operation time of the structural elements considering the operation load of the 50 and 60 years operation time.

The examination results show that the swelling and the irradiation induced stress corrosion crack are the most significant degradation mechanisms (among the degradation mechanisms) in the course of prolongation of the operation time of the RVI.

From the point of view of the swelling the critical environments are the follows: basket component at the middle part of the zone, baffle, fastener bolts and cylinder of the core basket.

Based on measurement results and the presumable irradiated and temperature data, with complete certainty cannot be excluded that $0.5-1.0 \%$ swelling will cause deformation, tightening in the fasteners bolts after 30 years operation time. The deformation of the baffle can influence the installation, assemblage and the joints too. The appearance of abrasion places on the matt surfaces will be the first sign of this deformation.

From the point of view of the irradiation induced stress corrosion crack the critical environment are the fastener bolts of basket, which can be characterized with fast irradiated neutron fluence and the stagnant environments.

The swelling caused hindered expansion of the bolt and the possible stress corrosion cracking of the bolts can lead to fracture. During the examination, for lack of other information, we supposed the preset load according to PNAE maximum. This is rather a conservative approach with a significant safety factor. To the determination of velocity of the crack propagation regarding the selected environments further analysis is needed.

\section{REFERENCES}

Strength analysis, fatigue analysis and thermal stratification analysis for systems, structures and components (SSCs) - reactor pressure vessel, steam generator, pressurizer, main circulating pump, main gate valve, pipelines, vessels, pumps, heat exchangers and valves - classified into the safety classes 1 and 2, Methodology and criteria documentation. (1)

Effect of irradiation on water reactors internals, Ageing Materials Evaluation and Studies (AMES) Report No. 11., Paris (1997). (2)

Hojna A., Ernestova M., Keilova E., Kocik J., Falcnik M., Kytka M., Pesek P., Rapp M., Material characterictics of materials from Greifswald active samples/active material database/core barrel, Report NRI Rez, DITI 302/419 Rev.3, (2007) (3)

CEA, TECNATOM and VTT, „Effect of Irradiation on Water Reactors Internals, AMES report No. 11, EUR 17694 EN, European Commission, Brussels-Luxemburg (1997). (4)

Regulations for strength analysis of equipment and piping of nuclear power plants, PNAE G-7-002-87, Energoatomizdat, Moscow (1989). (5)

Margolin B.Z., Kursevich I.P., Gulenko A.G., Vasina N.K., Minkin A.J., Buchatsky A.A., Generalization of experimental data and development of methods for prediction of physical -mechanical properties of irradiated material for pressure vessel internals concerning to the blocks 1-4 of the Paks Nuclear Power Plant, Final Connon Report Rev01, Saint-Petersburg, 2008. (6) 